УДК 341.48:343.533.6

https://doi.org/10.24866/1813-3274/2021-2/123-138

А. В. Даниловская ${ }^{1,}$ Хабаровский государственный университет экономики и права, г. Хабаровск, Россия

E-mail: d_a_v@list.ru

\title{
МЕЖДУНАРОДНЫЕ ОСНОВЫ УГОЛОВНО-ПРАВОВОЙ ОХРАНЫ КОНКУРЕНЦИИ
}

Аннотация. Вопросы охраны конкуренции и борьбы с наиболее распространёнными и опасными правонарушениями, совершаемыми против неё и в её сфере, широко обсуждаются мировым сообществом на площадках таких международных организаций, как ООН, ВТО, ЕАЭС, БРИКС. Однако каких-либо специальных международных конвенций, направленных непосредственно на защиту конкуренции, объединяющих на этой основе государства, являясь для них обязательными, в мире не существует. В то же время, в мире действует ряд международных актов, которые устанавливают ориентиры политики защиты конкуренции. Отдельные их положения, касающиеся вопросов уголовной ответственности за недобросовестную конкуренцию, определяют как её основания, так и санкции. Международное право устанавливает требования особой защиты от недобросовестной конкуренции с нарушением прав на объекты интеллектуальной собственности. При этом уголовная ответственность за антиконкурентные соглашения и иные виды антиконкурентной практики имеет исключительно рекомендательный для стран характер. Помимо традиционных антиконкурентных нарушений, ряд международных организаций указывает и на опасность сговоров на торгах и неисполнения требований антимонопольных органов, а также препятствования их деятельности. В числе рекомендуемых санкций - как за случаи грубого и намеренного серьёзного нарушения закона, так и за неисполнение правоприменительного постановления не только штраф, но и лишение свободы для физических лиц. В связи с особенностями внутригосударственных законов, приоритетом защиты национальных интересов, на практике возникает множество проблем во взаимодействии государств при рассле-

\footnotetext{
${ }^{1}$ Анна Владимировна Даниловская, кандидат юридических наук, доцент юридического факультета Хабаровского государственного университета экономики и права, г. Хабаровск, докторант Дальневосточного федерального университета, г. Владивосток, Россия.

Для цитирования: Даниловская А. В. Международные основы уголовно-правовой охраны конкуренции // Азиатско-Тихоокеанский регион: экономика, политика, право. 2021. №. 2. С. 123-138. DOI https://doi.org/10.24866/1813-3274/2021-2/123-138.
} 
довании антиконкурентных нарушений, в том числе влекущих уголовную ответственность, в частности, картелей. Однако, несмотря на это, страны демонстрируют намерение достичь консенсуса по наиболее сложным вопросам взаимодействия, а уже выработанные международными организациями предложения способствуют формированию внутригосударственных принципов защиты конкуренции, включая её уголовно-правовые аспекты.

Ключевые слова: международные конвенции, картель, сговор на торгах, антиконкурентные практики, злоупотребление доминирующим положением, недобросовестная конкуренция, уголовная ответственность, уголовно-правовая охрана конкуренции, ВТО, ООН, ОЭСР, СНГ, ЕАЭС, БРИКС.
A. V. Danilovskaia ${ }^{1}$, Khabarovsk State University of Economics and Law, Khabarovsk, Russia
E-mail: d_a_v@list.ru

\section{INTERNATIONAL FOUNDATIONS OF THE CRIMINAL LAW PROTECTION OF COMPETITION}

Abstract. The issues of protecting competition and combating the most common and dangerous offenses committed against it and in its sphere are widely discussed by the world community at the sites of such international organizations as the UN, WTO, EAEU, BRICS. However, there are no special international conventions aimed directly at protecting competition that would unite the states on this basis, being binding on them. At the same time, there are a number of international acts in the world that establish guidelines for competition protection policy. Some of their provisions concerning the issues of criminal liability for unfair competition determine both its grounds and sanctions. International law establishes requirements for special protection in relation to unfair competition with violation of rights to intellectual property. At the same time, criminal liability for anticompetitive agreements and other types of anticompetitive practices is exclusively advisory for countries. In addition to traditional anti-competitive violations, a number of international organizations also point to the danger of collusion in tenders and non-compliance with the requirements of antimonopoly authorities, as well as obstruction of their activities. Among the recommended sanctions, both for cases of gross and intentional serious violation of the law, and for failure to comply with

\footnotetext{
${ }^{1}$ Anna Vladimirovna Danilovskaya, Candidate of Law, Associate professor of the Faculty of Law, Khabarovsk State University of Economics and Law, Khabarovsk, doctoral student at the Far Eastern Federal University, Vladivostok, Russia.

For citing: Danilovskaya A. V. International foundations of the criminal law protection of competition // PACIFIC RIM: Economics, Politics, Law. 2021. No 2. P. 123-138. DOI https://doi.org/10.24866/18133274/2021-2/123-138.
} 
law enforcement order, not only a fine, but also imprisonment for individuals is suggested. Due to the peculiarities of domestic laws, the priority of protecting national interests, in practice, many problems arise in the interaction of states in the investigation of anticompetitive violations, including those that entail criminal liability, in particular, cartels. However, despite this, the countries demonstrate their intention to reach a consensus on the most complex issues of interaction, and the proposals already developed by international organizations contribute to the formation of domestic principles for the protection of competition, including its legal aspects.

Keywords: international conventions, cartel, bid rigging, anticompetitive practices, abuse of dominant position, unfair competition, criminal liability, criminal protection of competition, WTO, UN, ICN, OECD, CIS, EAEU, BRICS.

Международные акты, являясь в силу Конституции РФ составной частью правовой системы Российской Федерации, способны оказать существенное влияние на развитие внутригосударственных основ охраны конкуренции, включая их уголовно-правовые аспекты. Первым таким документом следует признать Парижскую конвенцию по охране промышленной собственности 1883 г., которая содержит общий запрет на недобросовестную конкуренцию и предусматривает не только её понятие и отдельные формы, но также обязывает страны-участницы конвенции обеспечить эффективную защиту от неё (ст. 10-bis).

Самые распространенные формы недобросовестной конкуренции связаны с неправомерным использованием объектов интеллектуальной собственности. Их международно-правовая защита основана на многочисленных международных конвенциях, но именно правовые акты ВТО призваны обеспечить их соблюдение и защиту при использовании объектов интеллектуальной собственности в сфере торговли и производстве. Большинство соглашений ВТО были приняты в результате переговоров Уругвайского раунда в период 1986-1994 г. В их числе Соглашение по торговле услугами (ГАТС) и Соглашение по торговым аспектам прав интеллектуальной собственности (ТРИПС), подписанные 15.04.1994 г.

Соглашение ТРИПС содержит достаточно определённые уголовно-правовые механизмы защиты интеллектуальных прав в международной торговле. В частности, согласно ст. 61 в странах-участницах конвенции уголовно-правовые меры должны применяться при умышленном подделывании товарных знаков, пиратстве в сфере авторского права в коммерческих масштабах, а также в иных случаях, если деяние совершено преднамеренно и в коммерческих масштабах. При этом в качестве средств правовой защиты участники конвенции должны предусматривать тюремное заключение и / или денежные штрафы, достаточные для обеспечения сдерживания в соответствии с уровнем наказаний, применяемых за 
преступления соответствующей тяжести, а также арест, конфискацию и уничтожение контрафактных товаров и любых материалов.

Вопросам политики защиты конкуренции, а также её влияния на международную торговлю посвящены п. 23-25 Декларации министров, принятой ВТО 14.11.2001 г. в г. Доха. В частности, стороны договорились о разработке положений о жёстких картелях. Однако специального документа о защите конкуенции в рамках ВТО пока не принято, хотя отдельные правила о конкуренции и внедряются в значимые международные акты ВТО, начиная еще с 1946 г. [1, с. 371-372].

Предпринимаются попытки решить проблемы охраны конкуренции на основе унифицированных правил и в рамках ООН. Так, в 1980 г. Конференцией ООН по ограничительной деловой практике, действующей под эгидой Конференции ООН по торговле и развитию - ЮНКТАД, принята резолюция, утвердившая Комплекс многосторонних согласованных принципов справедливости и Правила контроля ограничительной деловой практики (далее - Резолюция, Перечень правил ООН по вопросам конкуренции). Данным документом введено понятие ограничительной деловой практики, которой признано поведение предприятия, во-первых, представляющее собой злоупотребление доминирующим положением, ограничивающее доступ к рынкам или иным образом излишне сдерживающее конкуренцию, имеющее или способное оказать неблагоприятное воздействие на международную торговлю, и, во-вторых, посредством формальных, неформальных, письменных или устных соглашений имеющее аналогичное влияние. Закреплённые в Резолюции виды противоправных актов поведения нашли своё отражение в Типовом законе о конкуренции 2000 г. Основными среди них являются:

1. Ограничительные соглашения или договорённости между конкурирующими фирмами независимо от того, являются ли такие соглашения письменными или устными, официальными или неофициальными, если они представляют собой:

1) соглашения, устанавливающие цены или иные условия продажи, в том числе в международной торговле;

2) участие в торгах по тайному сговору;

3) соглашения о разделе рынков или покупателей;

4) ограничение производства или продажи, в том числе путем установления квот;

5) сговор об отказе от осуществления закупок;

6) сговор об отказе от осуществления поставок;

7) коллективный отказ в присоединении к договоренности или ассоциации, имеющей решающее значение для конкуренции.

2. Действия или поведение, представляющие собой злоупотребление доминирующим положением на рынке, в случаях:

1) когда предприятие, действуя либо самостоятельно, либо совместно с несколькими другими предприятиями, обладает возможностью контролировать соответствующий рынок конкретного товара; 
2) когда такие действия или поведение доминирующего предприятия ограничивают доступ к соответствующему рынку или иным образом неправомерно сдерживают конкуренцию, что оказывает или может оказать отрицательное влияние на торговлю или экономическое развитие.

Перечень правил ООН по вопросам конкуренции предусматривает основания для введения санкций и применения средств правовой защиты, среди них таковыми являются:

1) нарушения положений закона;

2) невыполнение решений или постановлений административного (антимонопольного) органа или соответствующего судебного органа;

3) непредоставление требуемой информации или документации в пределах установленного срока;

4) предоставление информации или выступление с заявлениями, которые являются ложными или вводящими в заблуждение.

Одним из видов санкций, рекомендованных для реагирования на случаи грубого и намеренного серьезного нарушения закона или правоприменительного постановления физическим лицом, названо лишение свободы.

Таким образом, принятая в 1980 г. Резолюция о Перечне правил ООН по вопросам конкуренции, будучи единственным универсальным международным актом в сфере политики защиты конкуренции, определяет общие критерии охранительных мер и призвана обеспечить взаимодействие между антимонопольными и иными органами всех стран-участниц ООН в сфере реализации международных правил конкуренции и её охраны. Однако она оказалась невоспринятой многими странами из-за попыток придать данному документу обязательный характер. Несмотря на это работа по принятию международного соглашения о конкуренции предпринимается теперь в рамках ВТО, что, однако, также вызывает возражения со стороны её отдельных членов [2].

Другой основой для формирования как международной, так и внутригосударственной политики защиты конкуренции является Организация экономического сотрудничества и развития - ОЭСР. Несмотря на то, что Россия не является её членом, она активно взаимодействует с этой международной организацией. ОЭСР рассматривает самые разные вопросы, связанные с охраной конкуренции, исследуя, в частности, возможности применения правовых средств защиты конкуренции на основе принципов международного права, но с учётом особенностей национальных законодательств и юрисдикций. В рамках ОЭСР приняты рекомендательные акты, ориентированные на оказание помощи странам в противодействии картелям, сговорам на торгах, злоупотреблению доминирующим положением, коррупции. Особое внимание организация уделяет опасности жёстких картелей. По этому поводу в 1998 г. приняты Рекомендации, адресованные членам ОЭСР, направленные на эф- 
фективное и рациональное противодействие картелям, включая жёсткие запреты, санкции не только за участие в картелях, но и за противодействие антимонопольным органам в их расследованиях в форме непредоставления требуемой информации. Приводится в Рекомендациях и довольно широкое понятие жёсткого картеля, к которым отнесены не только антиконкурентные соглашения, но и согласованная антиконкурентная практика.

Согласно Докладу о практике применения странами ОЭСР указанных Рекомендаций [3] политика введения высоких штрафов за картель является неотъемлемой частью успешной антикартельной программы, многие страны предусматривают их в своём законодательстве. Но всё же эти меры не являются достаточными для эффективного противодействия картелям. Поэтому странам рекомендовано устанавливать уголовную ответственность физических лиц за участие в картелях, проводить соответствующую работу среди правоприменителей, убеждая их в необходимости применения уголовно-правовых санкций в борьбе с картелями, налаживать взаимодействие между антимонопольными и правоохранительными органами. Помимо этого в Докладе указано на необходимость совершенствовать программы смягчения ответственности за картель, используя наилучшие практики [3, с. 39-40].

Учитывая распространённость сговоров на торгах и их опасность для экономик, в 2009 г., а затем в 2012 г. ОЭСР разработала Руководство по борьбе с фальсификациями заявок в сфере государственных закупок, призывая страны пересмотреть внутреннее законодательство, регулирующее закупки, а также правоприменение в этой сфере, с целью уменьшения рисков возникновения сговоров.

Однако следует отметить, что риторика ОЭСР относительно уголовной ответственности за картели меняется. В связи с проблемой доказывания картелей в уголовном процессе, а также некоторыми иными факторами, в т.ч. социального, этического характера, в ОЭСР признаётся недоказанность эффективности и целесообразности уголовной репрессии за картели, за исключением примера США. При этом в качестве причин декриминализации картелей в отдельных странах называются отсутствие знаний о законодательстве, предусматривающем уголовную ответственность за картели, более высокие стандарты доказывания в уголовном процесce, чем в гражданском, исключительный характер уголовной ответственности как меры за опасные преступления, к которым картель не относится, отсутствие вклада в общественное благосостояние со стороны осуждённых лиц и др. [4].

Важное прикладное значение имеет деятельность другого международного объединения - Международной конкурентной сети, члены которой являются представителями национальных антимонопольных органов. МКС занимается исключительно вопросами обеспечения соблюдения законов конкуренции, не руководствуясь при этом каким-либо правилами и не принимая обязательных или рекомендательных актов. Применять или не применять разработанные рабочими группами 
МКС руководства или лучшие практики в той или сфере конкуренции является внутренним и добровольным делом национальных антимонопольных органов [5].

Не существует правил международного характера, направленных на защиту конкуренции, и в БРИКС. Тем не менее, признавая значимость конкуренции и необходимость решения проблем в её сфере, странами-участницами этой международной организации принимаются различного рода документы, проводятся мероприятия, направленные на сотрудничество по вопросам конкурентной политики. Таковыми являются, например, Стратегия экономического партнёрства БРИКС 2015 г. (п. II.1), Совместное заявление руководителей конкурентных ведомств стран БРИКС 2015 г., Уфимская декларация (п. 25). С 2009 г. странами БРИКС регулярно проводятся Конференции по конкуренции под эгидой БРИКС, на которых обсуждаются вопросы политики защиты конкуренции и правоприменения в этой сфере, вырабатываются согласованные подходы к их решению.

Большое значение для развития внутренней политики защиты конкуренции в целом и уголовно-правовых норм за нарушение национального законодательства о защите конкуренции в частности имели и имеют международные соглашения, заключенные в рамках СНГ. Начало сотрудничеству в этой сфере было положено подписанием 12.03.1993 г. «Соглашения о согласовании антимонопольной политики», а затем сменившим его в 2000 г. «Договором о проведении согласованной антимонопольной политики». Указанные документы хотя и предусматривали некоторые материально-правовые нормы, но в основном были направлены на обозначение общих аспектов взаимодействия государств-участниц СНГ по вопросам совместной антимонопольной политики. Более детальное содержание антимонопольной политики стран СНГ было отражено в других документах - Рекомендательном законодательном акте «О защите экономической конкуренции», принятом Межпарламентской Ассамблеей государств-участников СНГ 17.02.1996 г., и схожем по структуре и содержанию с российским ФЗ от 26.07.2006 г. «О защите конкуренции» Модельном законе «О конкуренции», Утверждённом Решением Высшего Евразийского экономического совета от 24 октября 2013 г. Законодательным актом о защите экономической конкуренции странам СНГ (далее - Закон) было рекомендовано предусмотреть в своих национальных законах уголовную ответственность для должностных лиц органов исполнительной власти и местного самоуправления или хозяйствующих субъектов за ряд нарушений требований антимонопольного законодательства. В частности, основаниями уголовной ответственности предлагалось признать неоднократное совершение следующих действий: 1) осуществление регистрации хозяйствующих субъектов или их объединений без согласия органа по защите конкуренции при осуществлении им функций государственного контроля за созданием, реорганизацией, ликвидацией хозяйствующих субъектов и их объединений, а также непредоставление в срок по требованию органа по защите конку- 
ренции документов либо иной информации, необходимой для осуществления его деятельности в случаях, предусмотренных данным Законом (п. 3 ст. 20 Закона); 2) непредоставление органу по защите конкуренции ходатайств и заявлений, необходимых для осуществления им функций государственного контроля за созданием, реорганизацией, ликвидацией хозяйствующих субъектов и их объединений, а также для осуществления контроля за экономической концентрацией (п. 4 ст. 20 Закона).

Одновременно с указанным законодательным актом был принят Модельный Уголовный кодекс для стран-участниц СНГ, который содержит ряд уголовно-правовых норм, предусматривающих традиционные составы преступлений, совершаемых против добросовестной конкуренции. В частности, речь идет о ст. ст. 265 «Монополистические действия и ограничение конкуренции», 266 «Злостное нарушение порядка проведения публичных торгов или аукционов», 267 «Незаконное использование товарного знака», 268 «Заведомо ложная реклама», 269 «Незаконное получение информации, составляющей коммерческую или банковскую тайну», 270 «Разглашение коммерческой или банковской тайны», 254 «Воспрепятствование законной предпринимательской деятельности», ст. 161 «Нарушение авторских, смежных права и прав патентообладателей».

Следующим уровнем развития международных основ защиты конкуренции на территории бывшего СССР стал Таможенный союз, а затем - Евразийский экономический союз (ЕАЭС). Первоначально одной из правовых основ Единого экономического пространства, определяющего правила для конкуренции, стало Соглашение о принципах и правилах конкуренции 2010 г., позднее - отдельный раздел XVIII Договора о Евразийском экономическом союзе, подписанного в 2014 г. Следует отметить, что содержание договорно-правовой базы Таможенного союза и Единого экономического пространства было оптимизировано и приведено в соответствие с правилами ВТО [6].

Принцип эффективности санкций за совершение антиконкурентных действий, предусмотренный Соглашением о принципах и правилах конкуренции, ориентировал участников данного договора предусмотреть в своём законодательстве санкции в отношении как хозяйствующих субъектов, так и должностных лиц органов власти. При этом самые высокие размеры штрафов предполагались за нарушения, предусматривающие наибольшую угрозу для конкуренции. К последним, в частности, были отнесены антиконкурентные соглашения и злоупотребление доминирующим положением.

Об уголовной ответственности за антиконкурентные нарушения в рамках Единого экономического пространства впервые было сказано в проекте Модельного закона «О конкуренции» для стран Единого экономического пространства. В нём наряду с аналогичной нормой о штрафных санкциях Соглашения о принципах и правилах конкуренции содержалось общее установление возможности закрепления 
законодательством государств за нарушение законодательства о конкуренции помимо административной также и уголовной ответственности для физических и должностных лиц. Однако в дальнейшем это положение было изменено, и уже в окончательном тексте Модельного закона «О конкуренции» предусматривались подробные основания уголовной ответственности. К ним, в частности, отнесены:

1) заключение хозяйствующими субъектами, являющимися конкурентами, ограничивающего конкуренцию соглашения (картеля), а равно участие в таком соглашении,

2) неоднократное злоупотребление доминирующим положением, выразившееся в установлении и (или) поддержании монопольно высокой или монопольно низкой цены товара, необоснованном отказе или уклонении от заключения договора, ограничении доступа на рынок.

Договор о Евразийском экономическом союзе (далее - Договор) также предусматривает правила для конкуренции хозяйствующих субъектов и ее защиты. Особо в нем оговариваются запреты на соглашения между органами государственной власти, органами местного самоуправления, иными осуществляющими их функции органами или организациями или между ними и хозяйствующими субъектами, если такие соглашения приводят или могут привести к недопущению, ограничению или устранению конкуренции, за исключением случаев, предусмотренных Договором и (или) другими международными договорами государств-членов, а также запреты на предоставление государственных или муниципальных преференций, за исключением случаев, предусмотренных в законодательстве государствчленов и с учётом особенностей, предусмотренных Договором и (или) другими международными договорами государств-членов.

В Приложении 19 к Договору содержатся основания ответственности и размеры штрафов, налагаемых Евразийской экономической комиссией. Так, штрафами облагается следующее поведение хозяйствующих субъектов:

1) недобросовестная конкуренция,

2) заключение недопустимого антиконкурентного соглашения и участие в нём,

3) злоупотребление доминирующим положением,

4) координация экономической деятельности,

5) непредоставление, несвоевременное предоставление сведений в Евразийскую экономическую комиссию либо предоставление заведомо недостоверных сведений.

В Договоре повторяется правило о наиболее жёстких мерах ответственности за антиконкурентные соглашения и злоупотребление доминирующим положением. Следует отметить, что при этом, в отличие от предыдущих документов, в которых рассматриваемое правило касалось только картелей, в Договоре речь идёт в целом о соглашениях, ограничивающих конкуренцию. 
Согласно разделу IV Приложения 19, размеры штрафных санкций за недопустимые антиконкурентые соглашения и злоупотребление доминирующим положением, во-первых, исчисляются по единым правилам, во-вторых, имеют одинаковые размеры. То есть правовыми актами ЕАЭС признан одинаково опасный для конкуренции характер как недопустимых соглашений, так и злоупотреблений доминирующим положением. Такую ситуацию следует признать логичной, т.к. по своей сути антиконкурентное соглашение хозяйствующих субъектов - это форма запрещённой формы доминирования на рынке, характеризующаяся множественностью участников. Из данного вывода следует, что виды и меры ответственности, установленные внутренним законодательством за одинаково общественно опасные виды деяний, не должны быть принципиально разными.

Международные акты, принятые в рамках СНГ и ЕАЭС, имеют региональный характер и предопределены одинаковыми историческими и экономическими аспектами развития стран - их участниц, вследствие чего наблюдаются не только единообразие формирования современной системы права, но и общность подходов к определению направлений антимонопольной политики, а также стремление стран к объединению усилий по их реализации. Таким образом, наличие общих интересов, исходящих из исторически сложившихся предпосылок, может лечь в основу развития эффективных международно-правовых основ противодействия посягательствам на конкуренцию.

В научной литературе отмечается важность общности интересов, являющейся одним из главных факторов международного сотрудничества как по вопросам антимонопольной политики [7, с. 14], так и уголовного права [8, с. 13]. Именно этот принцип лежит в основе образования различного рода международных, межправительственных и межведомственных контактов.

Из анализа теории и практики международного взаимодействия по вопросам защиты конкуренции следует, что оно проявляется на двух уровнях - 1) в рамках соответствующих организаций универсального и специального характера деятельности и 2) в двусторонних - межправительственных и межведомственных - соглашениях государств. Принцип общности интересов имеет место на любом из указанным уровней, но представляется, что наиболее эффективным он может быть при реализации двусторонних соглашений межправительственного характера.

Другим важнейшим принципом взаимодействия антимонопольных и правоохранительных органов разных стран является так называемый принцип вежливости, проявляющийся через ограничение экстерриториальности действия национального антимонопольного закона и не всегда соблюдаемый странами при расследовании международных картелей. Так, на практике имеют место случаи, когда антимонопольный режим одной страны не учитывает национальные особенности антимонопольного законодательства и экономического развития другой страны и 
применяет свои правила в отношении сделок, заключённых за её пределами и не оказывающих какого-либо влияния на её рынок [9, 10]. Такого рода ситуации порождают вмешательство в суверенитет другого государства и, как следствие, конфликт и излишнюю напряженность межгосударственных отношений.

Между тем на 2020 г. Федеральная Антимонопольная Служба (ФАС) России подписала 24 меморандума о взаимопонимании или о сотрудничестве в сфере конкурентной (антимонопольной) политики, 14 соглашений о сотрудничестве в указанной сфере [11]. Однако проведённое интервьюирование представителей ФАС показало, что на практике достичь взаимопонимания по вопросам защиты конкуренции бывает непросто или невозможно, во-первых, из-за отсутствия универсального подхода к запретам тех или иных нарушений антимонопольного законодательства, в основном, в отношении понятия «картель», которое неодинаково трактуется в разных странах, являясь при этом основным нарушением международного характера, требующего взаимодействия, как минимум, двух стран; во-вторых, в связи с особенностью субъекта - участника международного картеля, которым нередко являются хозяйствующие субъекты, имеющие большое экономическое, порой стратегическое значение для государств, в которых они были учреждены, и привлечение которых к ответственности другой страной, в силу этого обстоятельства, исключено. Такие ситуации ведут к тому, что договоренности исполняются весьма поверхностно, ограничиваясь проведением совместных встреч, конференций, или не реализуются вовсе.

Двусторонние соглашения о сотрудничестве в области обеспечения соблюдения законодательства о конкуренции пока остаются наиболее распространённой формой межгосударственного взаимодействия. Основное в таких договорах - обмен информацией, что, однако, не может в полной мере удовлетворить потребности антимонопольных и правоохранительных органов в расследовании соответствующих дел [12, с. 52-56].

Для решения указанных проблем ФАС России разработала текст Конвенции по борьбе картелями, сферой применения которой рассматриваются рамки ЕАЭС именно здесь ожидается наибольший эффект от взаимодействия [13, с. 38-41]. Между тем международный акт универсального характера действия мог бы охватить собой гораздо большее количество участников, находящихся на разных этапах экономического развития, устранив имеющиеся проблемы с расследованием соответствующих дел, в то время как от сложившейся практики страдают развивающиеся страны - лишь немногим из них удается активно бороться с международными картелями [14].

Выявленная асимметрия вызвана целым рядом причин, которые связаны с отсутствием полноценного взаимодействия между странами при выявлении международного картеля [15]. Так, публичные сообщения органов развитых стран о рас- 
следовании ими международных картелей могут не содержать значимой для других стран информации, в силу чего последние вынуждены самостоятельно проводить расследования на предмет установления влияния международного картеля на их рынки. Помимо этого, у стран возникают и другие проблемы, которые в отсутствие универсальных правил взаимодействия существенно затрудняют им весь процесс расследования. Отчасти проблема связана с особенностями внутреннего законодательства, не предусматривающего основы взаимодействия не только с иностранными органами при выявлении и расследовании дел о картелях, но и между национальными антимонопольными и правоохранительными органами. Так, даже в рамках ЕАЭС такие правила предусмотрены лишь законами Республики Беларусь (ст.17 Закона от 12.12.2013 г. № 94-Ф3 «О противодействии монополистической деятельности и развитии конкуренции») и Казахстана (ст. 90-5 Предпринимательского кодекса Республики Казахстан от 29.10.2015 г. №375-V ЗРК). Помимо этого национальные законы могут содержать ограничения применения правил взаимодействия или такие его положения, которые станут обязательными для другой страны. Например, согласно Закону США о международном антитрестовском правоприменении 1994 г. помощь иностранному государству может быть оказана лишь при условии, что иностранный антимонопольный закон, применяемый иностранным антимонопольным органом, является уголовным [16].

В отсутствие специальных международных актов по борьбе с противодействиями конкуренции рассматривался вопрос о возможности применения к делам, возбужденным по признакам картеля с участием иностранных хозяйствующих субъектов, международных конвенций по борьбе с трансграничными правонарушениями, в частности, Конвенции ООН против транснациональной организованной преступности от 12.12.2000 г. Но применение к криминальным международным картелям указанного документа оказалось затруднительным в связи с различием тех или иных аспектов внутренней уголовной и конкурентной политики в сфере охраны конкуренции, а также наличием национальных стратегических интересов государства, связанных с деятельностью хозяйствующего субъекта-нарушителя. Практически нерешаемая проблема возникает при разной оценке картелей внутренним законодательством стран - слишком узкому понятию картеля в одной стране противостоит широкое в другой; отсутствие в стране уголовной ответственности за картель делает невозможным применение указанной конвенции к случаю участия в международном картеле хозяйствующего субъекта этой страны.

Тем не менее существует положительный опыт противодействия тем или иным преступлениям в сфере экономической деятельности $[17$, с. 20$]$, в том числе свидетельствующий о том, что ради общей цели пресечения противоправных, общественно-опасных деяний государства способны достичь консенсуса по многим спорным моментам соглашения. 
Таким образом, международные основы противодействия недобросовестной конкуренции представляют устоявшиеся и признанные государствами правила, включая уголовно-правовые, в то время как антимонопольное законодательство и его применение остаются довольно сложной темой для обсуждения на международном уровне, несмотря на внешне активные процессы, направленные на их форсирование. Попытки вывести на аналогичный уровень взаимодействие государств в связи с расследованием картелей пока ограничиваются межведомственными и межправительственными соглашениями об обмене информацией, хотя много внимания уделяется и работе над универсальными критериями защиты конкуренции, включая её уголовно-правовые аспекты. Представляется, что в основе достижения договоренности о едином понимании картеля, принципах взаимодействия между странами в лице антимонопольных и правоохранительных органов, исключающих влияние законодательства одной страны на правопорядок другой страны, а также беспрепятственный обмен информацией, должны быть общность интересов и действительная воля всех участников данного процесса.

\section{Список литературы}

1. Русин, К. ВТО как координатор в противодействии недобросовестной межстрановой конкуренции // Экономические науки. - 2009. - № 8 (57). - С. 368-372.

2. Переориентация глобальной торговли на благо людей. Перевод на русский язык Центра «Эко-Согласие» // Глобализация, ВТО и ННГ: расширение диалога для устойчивого развития. - URL: http://trade.ecoaccord.org/mgt/ (дата обращения: 02.08.2020).

3. Hard Core Cartels: Third report on the implementation of the 1998 Council Recommendation 2005 // ОЭСР : офиц. сайт. - P. 39-40. - URL: http://www.oecd.org/daf/ competition/cartels/35863307.pdf (дата обращения: 7.08.2020).

4. Global Forum on Competition: sanctions in antitrust cases. DAF/COMP/GF (2016)6. Р. 31-32 // ОЭСР : офиц. сайт. - URL: https://one.oecd.org/document /DAF/COMP/GF(2016)6/en/pdf (дата обращения: 7.08.2020).

5. What is the ICN? // ICN. - URL: https://www.internationalcompetitionnet work.org/about/ (дата обращения: 8.08.2020).

6. Конкурентное право в Евразийском экономическом союзе : учебное пособие для студентов высших учебных заведений / под общ. ред. М. А. Кусаинова, А. М. Джумабаевой, А. Г. Сушкевича, В. В. Савченко. - Москва, 2018. - 256 с.

7. Рокоссовская, В. В. Развитие международно-правового сотрудничества в области конкуренции : автореф. дис. ... канд. юрид. наук / В. В. Рокоссовская. Москва, 2004. - 17 с.

8. Спиридонов, А. П. Уголовное право Российской Федерации и правовая глобализация: влияние и соотношение : автореф. дис. ... д-ра юрид. наук / А. П. Спиридонов. - Санкт-Петербург, 2006. -48 с. 
9. Zelger, B. EU Competition law and extraterritorial jurisdiction - a critical analysis of the ECJ's judgement in Intel // European Competition Journal. - URL: https://doi.org/10.1080/17441056.2020.1840844 (дата обращения: 01.11.2020).

10. Choi, J. H., Park J. Y., Lee C. Cartels 2019: South Korea. Global Practice Guides // J. H. Choi, J. Y. Park, C. Lee. - URL: https://practiceguides.chambers.com/pr actice-guides/comparison/414/2796-2852/5677-5685-5686-5687-5688-5689) (дата обращения: 25.12.2020).

11. Соглашения о сотрудничестве: перечень документов // ФАС России : офиц. сайт. - URL: fas.gov.ru (дата обращения: 29.07.2020).

12. Кониева Ф. И. Практика расследования международных картелей: проблемы и пути решения // Российское конкурентное право и экономика. - 2017. № 1 (9). - С. 52-56.

13. Максимов, С. В. О перспективах принятия Конвенции Евразийского Экономического Союза о борьбе с картелями // Вестник Университета им. О. Е. Кутафина (МГЮА). - 2017. - № 9. - С. 38-41.

14. Трансграничная антиконкурентная практика: проблемы развивающихся стран и стран с переходной экономикой : записка секретариата ЮНКТАД от 12.04.2012 г. - URL: https://unctad.org/system/files/official-document/ciclpd16_ru.pdf (дата обращения: 04.10.2020).

15. Международное сотрудничество в соответствии с разделом F Комплекса согласованных на многосторонней основе справедливых принципов и правил для контроля за ограничительной деловой практикой: принятие руководящих принципов и процедур : записка секретариата ЮНКТАД, подготовленная в рамках Восьмой Конференция ООН по рассмотрению всех аспектов Комплекса согласованных на многосторонней основе справедливых принципов и правил для контроля за ограничительной деловой практикой, проведенной в Женеве 19-23 октября 2020 г. - URL: https://unctad.org/system/files/officialdocument/tdrbpconf5 d1_ru.pdf (дата обращения: 04.10.2020).

16. International antitrust enforcement assistance // US Department of Justice : ofic. site. - URL: https://uscode.house.gov/view.xhtml?req=granuleid\%3AUSC-prelimtitle15-chapter88\&edition=prelim (дата обращения: 10.10.2020).

17. Тенишев, А. П. Правовые инструментарии для противодействия международным картелям / А. П. Тенишев, М. А. Хамуков // Российское конкурентное право и экономика. - 2016. - № 2 (6). - С. 18-21.

\section{References}

1. Rusin K. VTO kak koordinator v protivodeistvii nedobrosovestnoi mezhstranovoi konkurentsii [WTO as a coordinator in countering unfair intercountry competition]. Ekonomicheskie nauki, 2009 no. 8 (57), pp. 371-372. 
2. Reorienting global trade for the benefit of people. Translation into Russian by the Eco-Accord Center. Globalization, WTO and NIS: Expanding Dialogue for Sustainable Development. Available at: http://trade.ecoaccord.org/mgt/ (accessed 02 August 2020). (In Russian).

3. Hard Core Cartels: Third report on the implementation of the 1998 Council Recommendation 2005. OECD website. Available at: http://www.oecd.org/daf/competitio n/cartels/35863307.pdf (accessed 07 August 2020).

4. Global Forum on Competition: sanctions in antitrust cases. DAF/COMP/GF (2016) 6. OECD website. Available at: https://one.oecd.org/document/DAF/COMP/GF (2016)6/en/pdf (accessed 07 August 2020).

5. What is the ICN? Website of the International Competition Network (ICN). Available at: https://www.internationalcompetitionnetwork.org/about/ (accessed 08 August 2020).

6. Kusainov M. A., Dzhumabaev A. M., Sushkevich A. G., Savchenko V. V. (general eds.). Konkurentnoe pravo v Evraziiskom ekonomicheskom soyuze : uchebnoe posobie dlya studentov vysshikh uchebnykh zavedenii [Competition law in the Eurasian Economic Union: a textbook for students of higher educational institutions]. Moscow, 2018. 256 p.

7. Rokossovskaya V. V. Razvitie mezhdunarodno-pravovogo sotrudnichestva voblasti konkurentsii [International legal cooperation in the field of competition]. Cand. Dis. (Legal. Sci). Synopsis. Moscow, 2004. 17 p.

8. Spiridonov A. P. Ugolovnoe pravo Rossiiskoi Federatsii i pravovaya globalizatsiya: vliyanie $i$ sootnoshenie [Criminal law of the Russian Federation and legal globalization: influence and correlation]. St. Petersburg, 2006. 48 p.

9. Zelger B. EU Competition law and extraterritorial jurisdiction - a critical analysis of the ECJ's judgment in Intel. European Competition Journal. Available at: https://doi.org/10.1080/17441056.2020.1840844 (accessed 01 November 2020).

10. Choi J. H., Park J. Y., Lee C. Cartels 2019: South Korea. Global Practice Guides. Available at: https://practiceguides.chambers.com/practiceguides/comparis on/414/2796-2852/5677-5685-5686-5687-5688-5689) (accessed 25 December 2020).

11. Cooperation agreements: list of documents. FAS Russia. Available at: fas.gov.ru (accessed 29 July 2020). (In Russian).

12. Konieva F. I. Praktika rassledovaniya mezhdunarodnykh kartelei: problemy i puti resheniya [Practice of investigation of international cartels: problems and solutions]. Rossiiskoe konkurentnoe pravo i ekonomika, 2017, no. 1 (9), pp. 52-56.

13. Maksimov S.V. O perspektivakh prinyatiya Konventsii Evraziiskogo Ekonomicheskogo Soyuza o bor'be s kartelyami [On the prospects for the adoption of the Convention of the Eurasian Economic Union on the fight against cartels]. Vestnik Universiteta im. O. E. Kutafina (MGYuA), 2017, no. 9, pp. 38-41.

14. Cross-border anti-competitive practices: problems of developing countries and countries with economies in transition: note by the UNCTAD secretariat dated 
12.04.2012. Available at: https:/unctad.org/system/files/official-document/ciclp d16_ru.pdf (accessed 04 October 2020). (In Russian).

15. International cooperation in accordance with section $F$ of the Multilaterally Agreed Equitable Principles and Rules for the Control of Restrictive Business Practices: Adoption of guidelines and procedures: note by the UNCTAD secretariat prepared in the framework of the Eighth United Nations Conference to Review All Aspects of the Multilaterally Agreed Set fair principles and rules for the control of restrictive business practices held in Geneva on 19-23.10.2020. Available at: https://unctad.org/system /files/official-document/tdrbpconf5d1_ru.pdf (accessed 04 October 2020).

16. International antitrust enforcement assistance. Official website of the US Department of Justice. Available at: https://uscode.house.gov/view.xhtml?req=granuleid \%3AUSC-prelim-title15-chapter88\&edition=prelim (accessed 10 October 2020).

17. Tenishev A. P., Khamukov M. A. Pravovye instrumentarii dlya protivodeistviya mezhdunarodnym kartelyam [Legal instruments for counteracting international cartels]. Rossiiskoe konkurentnoe pravo i ekonomika, 2016, no. 2 (6), pp. 18-21. 